\title{
Como promover exodontia segura para pacientes com angioedema hereditário?
}

\section{How to promote safe extraction patients with hereditary angioedema?}

Takuro Sanuki, Toshihiro Watanabe, Shinji Kurata, Takao Ayuse. Perioperative management of tooth extractions for a patient with hereditary. Journal of Oral and Maxillofacial Surgery. 2014 June. doi: 10.1016/j.joms.2014.08.026.

\section{Felipe Alan Romancini} Graduando de Odontologia na FOL/Unimep

O Angioedema Hereditário $(\mathrm{AEH})$ é uma doença genética causada pela deficiência de uma proteína chamada Inibidor de C1-esterase (C1-INH). Essa proteína normalmente ajuda o organismo a combater infecções e a controlar a coagulação do sangue e sangramentos. No paciente com angiodema, a deficiência de C1-INH causa um aumento da liberação de bradicinina, causando vasodilatação, levando à formação do edema nos tecidos vizinhos ao vaso dilatado.

As crises possuem caráter agudo, recorrentes e espontâneos de edema (inchaço) da pele. Os sítios geralmente acometidos são as extremidades corpóreas, ou seja, mãos, pés, braços, pernas, coxas, face e genitais, bem como as membranas internas como aparelho digestivo, laringe e garganta. E é neste ponto que se encontra a importância para a Odontologia, pois o edema d laringe é fatal em função do risco de sufocação (asfixia).

De acordo com a Associação Brasileira de Portadores de Angioedema Hereditário (Abranghe), as crises podem ser desencadeadas por diversos fatores como o estresse, trauma, menstruação, infecções e cirurgias. Com essas informações é possível questionar: Como o Cirurgião-Dentista poderá intervir cirurgicamente num paciente portador de AEH? Qual poderá ser o manejo odontológico pré e pós-operatório para que se faça exodontias nesse paciente?
Visando responder a essas perguntas, o presente artigo apresentou um relato de caso a respeito de avulsões dentárias em paciente com alto risco de ataque de laringe por $A E H$. A paciente, raça amarela, de 26 anos, portadora de angioedema hereditário, foi diagnosticada com pericoronarite, devido à erupção dos quatro terceiros molares, e se viu necessitada à remoção dos mesmos. Descobriu-se portadora de deficiência de $\mathrm{C} 1-\mathrm{INH}$ aos 24 anos com intensa dor abdominal e edema intestinal. Foi então medicada com ácido tranexâmico- 2000 $\mathrm{mg} / \mathrm{dia}$.

Para realizar as exodontias optoram pela sala de cirurgias do hospital universitário, dado à eventual necessidade de traqueostomia de emergência ou intubação. Como medida profilática foi administrado à paciente 1000 unidades de concentrado de C1 - INH ( Inativador Humano Liofilizado - C1, Berinert ; CSL Behring , Victoria , Austrália ) por via intravenosa uma hora antes da chegada na sala de cirurgia do HU.

No momento pré-cirúrgico a paciente demonstrou ansiedade, ou seja, quadro inicial de estresse. Assim sendo foi administrado para sua sedação $3,5 \mathrm{mg}$ de midazolam e infusão alvo-controlada de propofol $(1,8$ ug / ml). O flurbiprofeno axetil (50 mg) e paracetamol $(1000 \mathrm{mg}$ ) foram administrados por via intravenosa para controlar a dor pósoperatória. A anestesia local foi realizada com Lidocaína $1 \%$ sem vasoconstritor. 
Os sinais vitais da paciente foram controlados durante todo o procedimento, e mantiveram-se estáveis, o que representou um fator positivo com relação ao manejo do $\mathrm{AEH}$. O procedimento cirúrgico durou em torno de 31 minutos e o tempo de sedação foi de 56 minutos. A paciente foi transportada, logo em seguida, para a unidade de terapia intensiva, ficando sob observação durante 48 horas. Não foi observada complicações de saúde, nem ataques relativos ao angioedema, e após 3 dias recebeu alta.

Por esta experiência e o presente relato de caso, questões anteriormente levantadas podem ser sanadas, no que se refere à capacidade do Cirurgião-Dentista de intervir num paciente portador de $\mathrm{AEH}$ apenas a nível ambulatorial, ou semelhante ao caso, pacientes com alto risco de ataques laríngeos, é mais seguro que se realize numa sala cirúrgica devidamente equipada para atendimentos de emergência.

Para garantir o sucesso da cirurgia, é necessário um planejamento prévio e um protocolo medicamentoso eficaz. No presente trabalho, os autores optaram por administrar, por via intravenosa, de 500-1000 unidades de C1 - INH concentrado 1 hora antes da cirurgia, para evitar o ataque laríngeo induzido por $\mathrm{AEH}$ no período pré - operatório, o que se mostrou amplamente eficaz. Concomitantemente, a sedação induzida se faz necessária, visto que o estresse torna-se um grande vilão, podendo ser fundamental para desencadear crises sérias.

Os autores utilizaram como ansiolíticos midazolam e propofol, eficazes no controle da ansiedade. Não foi utilizado, para o procedimento, anestésicos locais com vasoconstritores, visto que a adrenalina é um dos agentes desencadeadores de crises de AEH.

Medicação analgésica para controle de dor pós-operatória também foi utilizada, de maneira intravenosa, o que contribuiu para uma recuperação confortável, e com redução do estresse devido ao controle da dor pósoperatória.

$\mathrm{O}$ atendimento de pacientes com $\mathrm{AEH}$ é de risco para o cirurgião-dentista? Sim, é. Entretanto, quando o conhecimento do problema é vizualizado e a necessidade de procedimentoscirúrgicoséeminente, apergunta a ser feita é como realizar atos cirúrgicos com segurança para o paciente? Quais os riscos e benefícios? Há que se responder positivamente a isso, de modo a utilizar os recursos de interação multidisciplinar e atuação hospitalar do profissional, salvaguardando o paciente de quaisquer complicações e riscos. 